\title{
Strategic Analysis of Coca-Cola Company based on Harvard Framework
}

\author{
Tianqi Luo \\ Central South University of Forestry and Technology, Changsha 410004, China
}

\begin{abstract}
Coca-Cola is the world's largest beverage company, with a global market share of $48 \%$. It has 160 beverage brands in 200 countries, including soft drinks, sports drinks, dairy drinks, fruit juices, tea and coffee. It is also the world's largest distributor of fruit drinks. Based on the Harvard framework, this paper analyzes the financial situation and marketing strategy of Coca Cola company and puts forward some development Suggestions.
\end{abstract}

Keywords: Harvard Framework; Financial Analysis; Strategic Analysis.

\section{Introduction}

Harvard analysis framework was originally put forward by three academics at the Harvard financial analysis framework, it from strategy analysis, accounting analysis, financial analysis and prospect analysis of four aspects carries on the analysis, and the traditional analytical framework through data quantitatively compared to financial analysis methods, Harvard analysis framework combining qualitative analysis and quantitative analysis, a more comprehensive analysis of the enterprise.

In the late 19th century, The Coca-Cola Company created a sales miracle by introducing coke with its unique taste and therapeutic effect on colds, and it still has the largest market share in the industry in the world, accounting for $70 \%$ of the market share in China, more than twice that of Pepsi. But now, as people pursue a healthy lifestyle, Coca-Cola needs to find new ways to maintain its position in tradition and innovation, not only to preserve flavor but also to reject carbonation and sugar. This makes the Coca - Cola company suffered a severe impact. The Coca-Cola company in recent years has been to improve your profits by cutting costs, such as first manufacturing raw stock to sell to other countries, and then bottle, it is beneficial to lower labor costs, but this is not a long-term strategy, so Coca-Cola company need to launch new products in various countries, to promote the improvement of income, this is the tao of Coca-Cola company for a long time.

In this paper, the Harvard analysis framework is used to analyze the financial situation of Coca Cola company and the reference Suggestions for the future development of the company are put forward based on the company's operating status and external environment.

\section{Report Analysis}

\subsection{Longitudinal Analysis}

Overall, most subjects of the balance sheet of Coca Cola company show a downward trend, while a few subjects show a slight upward trend from year to year. Except for a few subjects such as current liabilities show an upward trend, the balance sheet of Coca Cola company is still in the declining stage in general. From the perspective of the overall trend, this paper believes that the situation of Coca-Cola Company is not good. The total net assets of Coca Cola company decreased, but the total assets of Coca Cola company began to decline after reaching the peak in 2017. Monetary fund's not only show a downward trend, but the extent of its decline is also increasing year by year showing an accelerated decline. The total value of monetary funds in 2016 is almost twice as much as that in 2019. The amount of monetary fund's affects a company's solvency and is an important criterion for creditors to judge a company's credit. Moreover, the overall trend of current assets also shows a downward trend, as shown in Table 1, which shows a decline of 33\% from 2018 to 2019. The decline of total current assets has a negative impact on the company's credit rating and solvency. In addition, 
the speed of inventory turnover slows down and the total amount of inventory increases year by year. Therefore, this paper believes that the modern healthy diet has a negative impact on the sales volume of Coca Cola, and the company's capital recovery ability is negatively affected, resulting in the reduction of corporate monetary capital.

Table 1. Longitudinal Financial Analysis Table

\begin{tabular}{|c|c|c|c|c|c|}
\hline & 2016 & \multirow{2}{*}{2017} & 2018 & \multicolumn{2}{|c|}{2019} \\
\cline { 5 - 6 } & & & & ratio & Amount (100 million YUAN) \\
\hline Monetary fund & $199 \%$ & $185 \%$ & $143 \%$ & 100.00 & 111.75 \\
\hline Accounts receivable & $97 \%$ & $92 \%$ & $86 \%$ & 100.00 & 39.71 \\
\hline inventory & $79 \%$ & $79 \%$ & $82 \%$ & 100.00 & 33.79 \\
\hline Total current Assets & $167 \%$ & $179 \%$ & $150 \%$ & 100.00 & 204.11 \\
\hline Fixed assets & $98 \%$ & $76 \%$ & $76 \%$ & 100.00 & 108.38 \\
\hline Projects under construction & $93 \%$ & $117 \%$ & $109 \%$ & 100.00 & 198.79 \\
\hline Intangible assets & $79 \%$ & $62 \%$ & $65 \%$ & 100.00 & 267.66 \\
\hline Total assets & $101 \%$ & $102 \%$ & $96 \%$ & 100.00 & 863.81 \\
\hline Accounts payable & $24 \%$ & $20 \%$ & $22 \%$ & 100.00 & 113.12 \\
\hline Total current liabilities & $98 \%$ & $101 \%$ & $108 \%$ & 100.00 & 269.73 \\
\hline Total liabilities & $98 \%$ & $106 \%$ & $98 \%$ & 100.00 & 652.83 \\
\hline Total shareholders' Equity & $122 \%$ & $90 \%$ & $89 \%$ & 100.00 & 189.81 \\
\hline Potal liabilities and shareholders' equity & $101 \%$ & $102 \%$ & $96 \%$ & 100.00 & 863.81 \\
\hline P.S. takes 2019 as the base year, and then compares the data of the remaining years with that of 2019 to \\
\hline
\end{tabular}

Table 2. Analysis of trends in the income Statement of Coca-Cola Company from 2016 to 2019 (\%)

\begin{tabular}{|c|c|c|c|c|c|}
\hline \multirow{2}{*}{} & 2016 & 2017 & 2018 & \multicolumn{2}{|c|}{2019} \\
\cline { 5 - 6 } & & & & ratio & Amount (100 million YUAN) \\
\hline Operating income & $111 \%$ & $94 \%$ & $85 \%$ & 100.00 & 372.66 \\
\hline Operating cost & $114 \%$ & $91 \%$ & $80 \%$ & 100.00 & 146.19 \\
\hline Cost of sales & $127 \%$ & $104 \%$ & $85 \%$ & 100.00 & 121.06 \\
\hline Management fees & $991 \%$ & $55 \%$ & $-18 \%$ & 100.00 & 0.11 \\
\hline Finance charges & $72 \%$ & $80 \%$ & $93 \%$ & 100.00 & 9.46 \\
\hline Operating profit & $109 \%$ & $96 \%$ & $88 \%$ & 100.00 & 226.47 \\
\hline Profit total & $75 \%$ & $63 \%$ & $77 \%$ & 100.00 & 107.86 \\
\hline Less: Income tax expense & $88 \%$ & $309 \%$ & $90 \%$ & 100.00 & 89.2 \\
\hline Net profit & $73 \%$ & $14 \%$ & $72 \%$ & 100.00 & \\
\hline P.S. takes 2019 as the base year, and then compares the data of the remaining years with that of 2019 to \\
\hline
\end{tabular}


In 2017, the total value of coke's projects under construction reached the maximum. The total amount of projects under construction decreases after the completion of projects under construction. Fixed assets showed significant growth from 2018 to 2019, while intangible assets showed significant growth after 2018. Through the above analysis, it can be concluded that Coca-Cola hopes to attract a part of new consumers through innovation, and the construction of the project has laid a foundation for the company's future development.

As can be seen from Table 2, the operating revenue and operating cost of Coca-Cola decreased from 2016 to 2018, and recovered in 2019. The reason for the rebound in 2019 is that Coca-Cola invested a batch of products into the market in order to increase profits and increase revenue in 2018. Despite the weak sales of carbonated drinks, other core businesses such as tea, coffee and vitamin drinks made good profits in the market. Due to the public health consciousness enhancement, more and more people realize the harm of carbonated drinks, led to the Coca-Cola mainstream product sales are threatened, net income reached its lowest point in 2017, at the same time, in 2017, the income tax expenses of abnormal is higher than other years, in 2019 net profit reached the highest in these four years. As can be seen from Table 2, operating income gradually decreases with the reduction of operating costs. From 2016 to 2019, Coca-Cola's non-operating income and non-recurrent expenses have a great impact on its final net profit value. The reason is that the Coca-Cola Company has reduced unnecessary costs. For example, 1 . The original factory was dismantled and the coke pulp was shipped to various countries for processing and production of bottled coke. 2 . Reduce processing procedures, reduce the number of employees, select OEM factories for processing, and reduce the company's manpower, equipment purchase, maintenance and other costs.

Table 3. Statistical Table of trend Analysis of cash flow statement of Coca-Cola 2016-2019 (Unit: 100 million YUAN)

\begin{tabular}{|c|c|c|c|c|}
\hline & 2016 & 2017 & 2018 & 2019 \\
\hline Net cash flow from operating activities & 87.96 & 69.95 & 73.2 & 104.71 \\
\hline Net cash flow from investment activities & -9.99 & -23.77 & 64.39 & -39.76 \\
\hline Net cash flow from financing activities & -65.45 & -74.09 & -105.52 & -90.04 \\
\hline
\end{tabular}

Cash flow from operations has increased after a brief decline. The reasons for this trend are as follows: 1. Changes in sales volume. 2. In 2016 and 2017, some buyers made credit payments, so accounts receivable were relatively high and the cash flow generated was not fully positively correlated with the operating income. 3. From 2016 to 2017, Coca-Cola's foreign investment increased significantly. In 2018, it recovered a large amount of investment and received investment income, and in 2019, it started a new round of foreign investment. Financing has been maintained by a large amount of external cash flow that may be repaid by borrowing.

\section{SWOT Analysis of Coca-Cola Company}

\subsection{Coca-Cola's Advantages}

Coca-Cola's strengths lie in the following aspects. 1 . There are many products, which can meet the needs of more consumers. Among them, the old product Coca-Cola is popular with consumers for its unique taste. Once, because of the competition with Pepsi, Coca-Cola Company decided not to produce the original Coke, which made people realize the irreplaceable of the classic taste and even broke out the Cola parade in support of the original Coke. In spite of this, not everyone likes CocaCola, so Coca-Cola has been optimizing its taste, upgrading its formula, and adding fresh and unique flavors. Moreover, the Company has many brands, and through continuous segmentation of the market, it has launched more kinds of drinks to meet different consumer needs. 2 . The formation of Coca Cola brand effect [1] and its influence on corporate culture worldwide. After officially 
becoming a national brand and establishing its irreplaceable classic taste image, Coca-Cola once again conquered the people and established a spiritual image in the army by selling it to the soldiers at a very low price during The Second World War. The Coca-Cola Company printed a booklet entitled "The Importance of Completing the Toughest Combat Tasks and Rest". The pamphlet stresses that because of the needs of soldiers on the battlefield, coke has become not just a leisure drink, but a necessity, as important as guns and ammunition. Coke's strategy was politically correct and propagated an image of patriotism that left a lasting impression on the public, and for the soldiers the smell would lure them back to their homeland in triumph. Coca-Cola has been sponsoring the Amsterdam Olympics since 1928. The close cooperation between Coca-Cola and the Olympic Games is of great long-term benefit to Coca-Cola's further expansion into the world market. Coca Cola enjoys the dividend of the Olympic culture and earns considerable income. Now, the consistent image of Coca-Cola in people's mind is combined with the spirit of "higher, farther and stronger" of The Olympic Games. It is the excited mood when watching the games and the release and relief after the wanton sweat, which makes the passionate spirit of Coca-Cola deeply rooted in people's hearts [2]. So much so that watching a game or a movie without buying a coke feels like something is missing. 3. Coca-Cola's marketing strategy is characterized by localization. Aimed at the particularity of each country produced different advertising system, such as China, Coca-Cola took a lot of advertisements about Spring Festival family reunion, and for now the social status quo, which reduce face-to-face communication between people, took a lot of coke put mobile advertising, between the relatives for the elderly is a kind of attraction. In addition, celebrity endorsement is also a major weapon. For ordinary consumers, there seems to be no difference between the two brands of Cola, but celebrity endorsement will attract many fans to buy it. Coca-Cola will also launch a special edition package for celebrities [3]. 4. Coca Cola has always been committed to green development. Sustainable international development requires enterprises to have a certain sense of social responsibility, which is very important for national enterprises such as Coca Cola. In 2016, Coca-Cola released its "Green Annual Report", focusing on seven areas: agriculture, human rights and labor rights, packaging and recycling, water resources management, climate protection, giving back to society and empowering women's economy. Among them, packaging and recycling are the most closely related to Coca-Cola company. Moreover, the treatment and recycling of plastic bottles is an important topic for the whole world, because plastic bottles are not easy to decompose and the decomposition materials are toxic, so that the global ecosystem has been damaged. And if you want to keep the traditional packaging, but at the same time to achieve the purpose of protecting the environment requires companies to spend more money to buy decomposable material production bottles, and plastic bottles for recycling reproduction, this undoubtedly in early would increase the cost of a large part of the Coca-Cola company, but in order to achieve the sustainable development of Coca-Cola company still bear the social responsibility, for the enterprise's reputation has a lot to improve [4]. Therefore, consumers who are aware of these facts are more likely to buy the beverages produced by Coca-Cola, which leads to the fact that other beverage companies need to take the same responsibility to protect the environment in order to gain market competitiveness. But as the first to implement the strategy, the company will undoubtedly accumulate deeper social influence and seize more market share.

\subsection{Disadvantages of Coca-Cola Company}

Coca-Cola's disadvantages including: 1 . the launch of the mainstream of commodity is not friendly to health, long-term drinking carbonated drinks can lead to many diseases, or worse, including lead to osteoporosis caused by loss of calcium, lead to obesity, too much gas in the carbonated drinks can also cause bilge gas, indigestion and other gastrointestinal problems, and that of high phosphate can cause kidney stones. This is the biggest disadvantage of Coca-Cola. Due to the lack of characteristics of carbonated drinks, many sick people and health-seeking people will not buy carbonated drinks. 2 . Disadvantages of price and products. Coke's retail price is higher than Pepsi's retail price and Pepsi's bottle is larger than coke's. Consumers will no doubt choose Pepsi that looks more affordable. And Pepsi often offers special deals: coupons, discounts, bundling and so on to attract consumers. 


\subsection{Development Opportunities for Coca-Cola Company}

Nowadays many young people tend to low sugar low fat, healthy life, better manage their bodies and health, if we can production can meet the demand of their healthy drinks, Coca-Cola can also get this part of the consumer, and the WHO add sugar intake should be limited in the light of consumer advice, the Coca-Cola company launched a coke zero through innovation, is committed to using xylitol instead of sugar in the case of the original flavor unchanged meet the need of this part of the crowd without sugar. Not only that, but in order to meet the needs of more consumers in different occasions, Coca-Cola has introduced smaller and more convenient packaging, which has been introduced in 140 countries; Forty percent of the company's soda brands have introduced packs of no more than 250 milliliters.

Big under the background of the level of economic development, reducing poverty, make the low level of consumer goods increased purchases, for instance, when new China was just as Coca-Cola is a kind of luxury consumption, but now coke tends to be a common brand, and people's living standards rising makes more people to the pursuit of spiritual pleasure, so such as cinema, KTV entertainment industry will also drive the development of this kind of product consumption growth.

\subsection{Development Threats of Coca Cola}

Competition from other companies is obviously the biggest threat to Coke, among which the biggest competitor is Pepsi, which has similar products to coke, and also gets the majority of people's feedback that Pepsi tastes better when people rate themselves. In China, PepsiCo has partnered with fast-food companies such as KFC and increased its exposure by sponsoring well-known variety shows. But the rivalry between the two has become more benign. Therefore, Coca-Cola launched the rest of the threat from the meteoric rise of fruit juice, tea beverages company, although the Coca-Cola have occupied the majority of market share, but when the rise of more new beverage company, to break the original market pattern, coke's largest under pressure, because when the emerging company receive a $20 \%$ market share, the number of the Coca-Cola company will lose more customers. Moreover, this kind of drink seems to be more healthy. Healthy and tasty is undoubtedly the biggest selling point of the product, which can meet the needs of almost all people.

Plate on the other hand is one of the world market from development to today, basic has been stable, in addition to consumption ability is lower Africa also has the prospect of the market, in other countries Coca-Cola has basic popularity in the market, Coca-Cola wants to get more customers will need to fight for market share with other beverage company. However, taking The Chinese market as an example, Coca Cola entered a weak period and its sales volume was hit, so it chose some costcutting methods to maintain the stability of profits. But it's not going to be a long-term solution. It's going to have to break out of what Coke has done and create some new value.

\section{Summary}

From the point of view of the labor of Coca-Cola company to launch more in line with consumers expect commodity can solve the problem of coke current biggest breakthrough, for consumers the Coca-Cola company's biggest selling point is its traditional commodity coke, Sprite and so, the United States in the carbonated soft drinks, for now, the basic can't resolve its shortcomings, so can only launch a series of health drinks market test market feedback. Other drinks are not a commodity that everyone needs so it is a very difficult market according to the conventional way of dividing markets such as age or gender, can only differentiate according to the degree of love, so do enough market research can give Coca-Cola and stable customer groups, make people become loyal customers prefer Coca-Cola company product, this group of people to drive around the friend family buy Coca-Cola in the eve of the party. In the face of large customers such as enterprises, Coca Cola can directly supply and sell, and the channel is fast and convenient and the purchase price is cheap, which is obviously a hard power for buyers. At the same time, Coca-Cola should attach importance to the information exchange between the company and customers, such as creating some public accounts 
for customers to make some feedback or questionnaire surveys, releasing some welfare information and giving some coupons on the public accounts, which can effectively retain customers. Send some gifts to customers on their birthdays to make them feel the humanistic care of Coca Cola. High quality service and affordable price is the absolute weapon for firm customers. Coca-Cola should reasonably allocate resources to transfer the production lines of some products with low sales volume in the past to the hot products with high sales volume. It can also allocate a batch of production lines to produce new products and carry out market research and analysis on customer feedback.

\section{References}

[1] Juntao Xie. Analysis of Coca-Cola brand IP Marketing. Popular Literature and Art, 2019, p.155.

[2] Yaoda Qin. The influence of Olympic Marketing on Coca-Cola brand culture. Beijing Sport University, 2015.

[3] Jingyi Nie. A Comparative Study on Advertisement between Pepsi and Coca Cola. China Market, 2019 (20).

[4] Coca-Cola supports China's circular economy. Green Packaging, 2019, p.24-25.

[5] FEATURE Fast Elimination, Vol.546(2018) No.10, P.56-59.

[6] Aifeng Chen. Analysis on the network Marketing strategy of Coca - Cola in China. Liaoning University, 2015. 